\title{
Standards Used by a Clinical and Scientific Endometriosis Center for the Diagnosis and Therapy of Patients with Endometriosis
}

\section{Standards für die Diagnostik und Therapie von Patientinnen mit Endometriose an einem klinischen und wissenschaftlichen Endometriosezentrum}

\section{(c) $9 \ominus$}

Authors

Stefanie Burghaus ${ }^{1}$, Thomas Hildebrandt ${ }^{1}$, Christine Fahlbusch ${ }^{1}$, Katharina Heusinger ${ }^{1}$, Sophia Antoniadis ${ }^{1}$, Johannes Lermann $^{2}$, Janina Hackl ${ }^{1}$, Lothar Häberle ${ }^{3}$, Stefan P. Renner ${ }^{4}$, Peter A. Fasching ${ }^{1}$, Matthias W. Beckmann ${ }^{1}$, Simon Blum ${ }^{1}$

\section{Affiliations}

1 Frauenklinik, Universitätsklinikum Erlangen, UniversitätsEndometriosezentrum Franken (UEF), Erlangen, Germany

2 Klinik für Gynäkologie und Geburtshilfe, Klinikum Bayreuth, Bayreuth, Germany

3 Abteilung für Biostatistik, Frauenklinik, Universitätsklinikum Erlangen, Erlangen, Germany

4 Frauenklinik, Klinikum Sindelfingen-Böblingen, Böblingen, Germany

Key words

endometriosis, sterility, lower abdominal pain, diagnostic

Schlüsselwörter

Endometriose, Unfruchtbarkeit, Unterleibsschmerzen, Diagnostik

received 26.8.2018

revised $\quad 30.10 .2018$

accepted 4.12.2018

Bibliography

DOI https://doi.org/10.1055/a-0813-4411

Published online 28.2. 2019 | Geburtsh Frauenheilk 2019; 79: 487-497 @ Georg Thieme Verlag KG Stuttgart · New York I ISSN 0016-5751

Correspondence

Dr. Stefanie Burghaus

Frauenklinik, Universitätsklinikum Erlangen

Universitätsstraße 21-23, 91054 Erlangen, Germany

Stefanie.Burghaus@uk-erlangen.de

Deutsche Version unter:

https://doi.org/10.1055/a-0813-4411

Supporting Information:

https://doi.org/10.1055/a-0813-4411

\section{ABSTRACT}

Endometriosis is one of the most common benign gynecological diseases. The extremely heterogeneous complex of symptoms complicates the diagnosis and treatment of this disease. In most patients, there is a latency period of several years between the first occurrence of symptoms and the definitive diagnosis. This paper aims (1) to evaluate standards for the diagnosis and treatment of patients with (symptoms suspicious for) endometriosis in terms of feasibility, and (2) to assess the potential use of data collected by a certified clinical and scientific endometriosis center to answer scientific questions. Standards for outpatient consultations were developed for a special endometriosis outpatient clinic. Between January 2014 and December 2017, a total of 1715 outpatients with a suspicion of endometriosis presented to this special endometriosis outpatient clinic; the diagnosis and treatment of patients was carried out in accordance with the developed standards. Data of this patient cohort obtained from patient records created during outpatient consultations and from a questionnaire recorded in an Oracle-based database was analyzed. The patient cohort was also compared with another patient cohort who had attended different outpatient clinics and had been diagnosed intraoperatively with endometriosis. $41.8 \%$ of patients examined during special outpatient consultations had surgery for suspicion or recurrence of endometriosis. Endometriosis was confirmed in $81.5 \%$ of cases. Pain symptoms were the main indication for surgery in $70.1 \%$ of cases compared to $45.1 \%$ of cases in the comparison group. The structured approach used in the special endometriosis outpatient clinic is a key aspect of the care provided by the certified clinical and scientific endometriosis center. It ensures that patients are diagnosed and treated in accordance with guideline recommendations, that diagnosis and treatment comply with certification requirements, and that the collected data can be used to answer scientific questions. 


\section{ZUSAMMENFASSUNG}

Endometriose zählt zu den häufigsten gutartigen gynäkologischen Erkrankungen. Ein sehr heterogener Symptomkomplex erschwert die Diagnose und die Therapie der Erkrankung. Meist besteht eine mehrjährige Latenz zwischen dem erstmaligen Auftreten von Symptomen und der Diagnosestellung. Ziel der vorliegenden Arbeit sind (1) die Überprüfung von definierten Standards für die Diagnostik und die Therapie von Patientinnen mit (Verdacht auf) Endometriose auf ihre Umsetzbarkeit und (2) eine mögliche Nutzung dieses zur Beantwortung von wissenschaftlichen Fragestellungen als Grundlage im zertifizierten klinischen und wissenschaftlichen Endometriosezentrum. In der Spezialambulanz für Endometriose wurde ein Standard für die Durchführung dieser Sprechstunde entwickelt. Im Rahmen dieser Spezialambulanz erfolgten 1715 ambulante Patientenvorstellungen von Januar 2014 bis Dezember 2017, wegen der (Verdachts-)Diagnose Endometriose, die nach diesem Standard diagnostiziert und behandelt wurden. Anhand der
Dokumentation der Patientinnenakte und des Fragebogens in einer Oracle-basierten Datenbank wurde eine Analyse des aus dieser Sprechstunde hervorgehenden Patientenkollektivs durchgeführt. Zudem wurde ein Vergleich mit dem Patientinnenkollektiv durchgeführt, das sich in anderen Spezialambulanzen vorgestellt hat und bei dem intraoperativ ebenfalls Endometriose diagnostiziert wurde. $41,8 \%$ der Patientinnen aus dieser Sprechstunde wurden bei Verdacht auf Endometriose oder dem Rezidiv einer Endometriose operiert. Eine Endometriose konnte bei $81,5 \%$ bestätigt werden. Die Schmerzsymptomatik war in 70,1\% die Hauptindikation für die Operation, im Vergleichskollektiv war diese $45,1 \%$. Die vorgestellte Strukturierung einer Spezialambulanz für Endometriose als zentraler Bestandteil eines zertifizierten klinischen und wissenschaftlichen Endometriosezentrums ermöglicht eine leitliniengerechte Diagnostik und Therapie der Patientinnen mit Endometriose, die Erfüllung der Zertifizierungsvoraussetzungen und das Beantworten von wissenschaftlichen Fragestellungen.

\section{Introduction}

Endometriosis is associated with a range of different clinical symptoms. The tentative diagnosis may be based on menstrual cyclerelated pain, chronic pain or infertility, and the definitive diagnosis is then confirmed by diagnostic laparoscopy. However, endometriosis may also be diagnosed as an incidental finding in asymptomatic patients. Around $25-30 \%$ of women between the ages of 25 and 35 years are affected by this disease [1,2]. The prevalence of endometriosis among sterile women is even higher, with a reported incidence of up to $50 \%$ [3-5]. According to data from the German Federal Statistical Office, 27113 patients with endometriosis were hospitalized in Germany in 2016 and had conservative or surgical treatment. Because of the very heterogeneous presentation of the disease, it is assumed that the number of patients with non-surgically diagnosed endometriosis is significantly higher [6].

Although gynecological research is becoming increasingly aware of endometriosis, it is still assumed that the average latency period between the first appearance of symptoms and the definitive diagnosis is around 10 years [7]. This delay does not just put patients under considerable psychological strain and reduces their quality of life, it also leads to higher healthcare costs due to frequent visits to different physicians and unnecessary or futile diagnostic and therapeutic procedures and limits patients' capacity to work [8-11]. Establishing a consistent structure for special endometriosis outpatient clinics is necessary to enable treating physicians to make comparable, efficient and specific diagnoses and promptly prescribe the appropriate therapeutic measures.

To improve the quality of medical care, research, and teaching, a certification process for endometriosis centers was introduced by the Stiftung Endometriose-Forschung (SEF), the European Endometriosis League and the self-help group Endometriose Vereinigung Deutschland e. V. in 2006 [12]. It uses a phased approach and defines the requisite criteria for certification. According to the criteria, diagnosis and treatment must be carried out in ac- cordance with appropriate guidelines, the center must work together with self-help groups, the patient's medical history must be recorded, and the center must compile an annual report. The standards differentiate between

1. gynecological practices,

2. centers of reproductive medicine,

3. rehabilitation clinics,

4. centers with only one surgeon specialized in treating endometriosis, and

5. hospitals and surgical day clinics, which can be certified as clinical or clinical and scientific endometriosis centers.

Patients have also taken note of this new certification process. In a multicenter study, 2500 patients were asked what they knew about certified centers, and $43.8 \%$ of respondents reported that they had deliberately contacted a certified center to obtain a diagnosis and treatment [13].

This study aimed to evaluate the feasibility of the standards developed for certified clinical and scientific endometriosis centers to diagnose and treat patients with (symptoms suspicious for) endometriosis and analyzed a patient cohort diagnosed with endometriosis to determine whether additional scientific questions need to be asked. A model for the organizational structure of special endometriosis outpatient clinics and for the necessary diagnostic and therapeutic procedures is presented here, and aims to define professional clinical standards.

\section{Patients and Methods}

In 2006, a standardized special endometriosis outpatient clinic was set up in the Gynecology Department of the University Hospital of Erlangen and certified as a highest-level endometriosis center. Outpatient clinics are held twice a week; they are staffed by specialists who have additional qualifications/have undergone advanced training in endometriosis. Patients present to the clinic after a referral by their gynecologist or on their own initiative after 
they have researched the options themselves. A diagnostic and therapeutic approach was developed, based on the most important symptoms of disease. The feasibility of the approach was retrospectively evaluated in this feasibility study.

\section{Standards for special outpatient endometriosis clinics within certified endometriosis centers}

Before the patient first presents to her physician, she is given a case-history questionnaire to complete which contains detailed questions about her general medical and gynecological history. The patient is additionally given a specific questionnaire with questions which focus on typical endometriosis-related complaints. In addition to the case-history questionnaire, the patient is given a further questionnaire with questions which aim to answer a number of scientific questions. During the subsequent indepth talk with the treating physician, the patient's individual answers are discussed and amplified. The patient's history of symptoms is recorded, with a special focus on symptoms typical for endometriosis ( $\triangleright$ Fig. 1). Particular importance is attached to the patient's report on the extent of pain she experiences, which she rates using a numeric analog scale with values between 1 and 10 .

After the completed questionnaires have been handed in, the first diagnostic procedure consists of a general gynecological examination and ultrasound ( $\triangleright$ Fig. 2). Ultrasound by itself is not enough to make a diagnosis of endometriosis or exclude it. However, ultrasound can be used to detect the presence of ovarian endometrial cysts (also known as an endometrioma), assess the condition of the uterus including indications for adenomyosis, detect adhesions in the inner genital region, and evaluate uterine motility status and any thickening of the intestinal wall in cases where the intestines are also affected [14-16]. Renal ultrasound should be carried out in addition to gynecological ultrasound to exclude asymptomatic hydronephrosis caused by deep infiltrating endometriosis affecting the ureters.

Symptom-based diagnostic procedures are carried out to investigate endometriotic symptoms ( $>$ Fig. 3 ). Clinical examinations are of only limited use to diagnose deep infiltrating endome-

\begin{tabular}{|c|c|}
\hline \multicolumn{2}{|c|}{ Medical history } \\
\hline$\nabla$ & $\nabla$ \\
\hline $\begin{array}{l}\text { General medical history: } \\
\text { Menstrual history } \\
\text { - Gravidity/parity } \\
\text { Previous therapies } \\
\text { Previous operations } \\
\text { - Medication } \\
\text { (previous and current) } \\
\text { Additional diagnoses } \\
\text { Allergies } \\
\text { Body mass index } \\
\text { Familial history } \\
\text { Social history }\end{array}$ & $\begin{array}{l}\text { Symptom-based } \\
\text { medical history: } \\
\text { Dysmenorrhea } \\
\text { - Lower abdominal pain } \\
\text { Dyschezia/ } \\
\text { hematochezia } \\
\text { Dysuria/hematuria } \\
\text { Dyspareunia } \\
\text { Sterility } \\
\text { - Asymptomatic }\end{array}$ \\
\hline
\end{tabular}

- Fig. 1 Standards for taking the general and symptomatic gynecological history of patients with endometriosis or symptoms suspicious for endometriosis.

triosis. For certain clinical conditions such as deep infiltrating endometriosis of the ureter with hydronephrosis, magnetic resonance imaging is required to determine the extent of disease. Magnetic resonance imaging (MRI) and transvaginal ultrasound are equivalent in terms of making a diagnosis. However, MRI is more sensitive for detecting endometriotic foci in the vagina and uterosacral ligaments [17]. When patients present with chronic pain of the lower abdomen, close cooperation with a gastroenterologist is recommended to investigate and exclude other possible causes such as food intolerances, chronic inflammatory bowel dis-

\begin{tabular}{|c|c|c|}
\hline \multicolumn{3}{|c|}{ Basic diagnostic procedures } \\
\hline$\downarrow$ & $\downarrow$ & 7 \\
\hline $\begin{array}{l}\text { Inspection/speculum examination } \\
\text { - Genitals/vagina } \\
\text { - Posterior vaginal fornix }\end{array}$ & $\begin{array}{l}\text { Bimanual vaginal and rectal } \\
\text { palpation } \\
\text { - Uterus } \\
\text { - Bil. uterosacral lig. } \\
\text { - Bil. adnexa } \\
\text { - Parametria } \\
\text { - Pouch of Douglas } \\
\text { - Rectovaginal septum }\end{array}$ & $\begin{array}{l}\text { Vaginal ultrasound } \\
\text { - Uterus (signs of adenomyosis) } \\
\text { - Ovaries } \\
\text { - Intestines } \\
\text { - Bladder } \\
\text { Renal ultrasound }\end{array}$ \\
\hline
\end{tabular}

- Fig. 2 Standards for basic diagnostic procedures for patients with (symptoms suspicious for) endometriosis. Bil. = bilateral. 


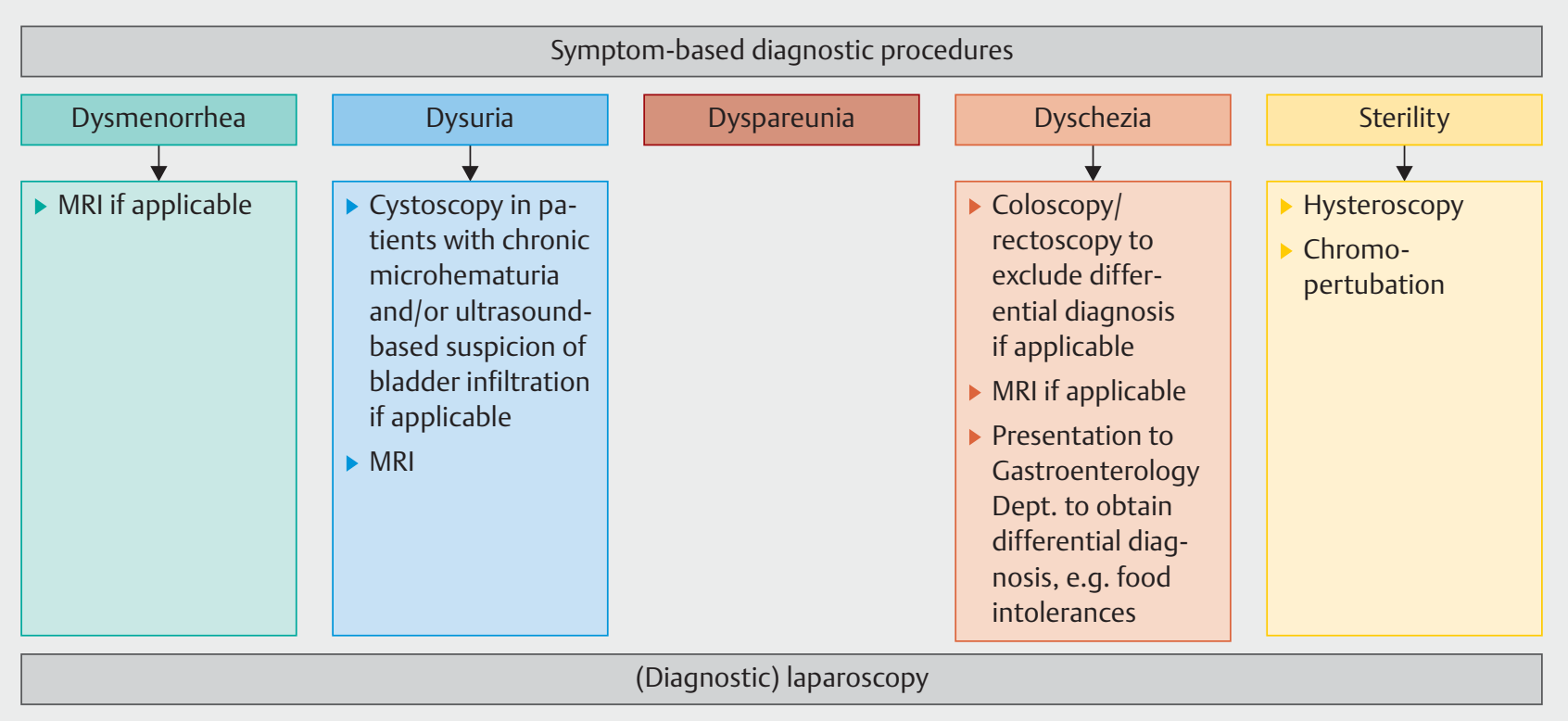

- Fig. 3 Symptom-based diagnosis of patients with (symptoms suspicious for) endometriosis. MRI = magnetic resonance imaging.

ease or irritable bowel syndrome and to obtain a differential diagnosis.

The third and last step of the treatment algorithm consists of developing an individual, guideline-based and, where necessary, interdisciplinary treatment concept for the respective patient ( $\vee$ Fig. 4). The treatment of endometriosis rests on two pillars: surgery and conservative management [18-20]. The choice of therapy is guided by the patient's symptoms and the patient's reasons for presenting to the outpatient clinic and by the time and type of diagnosis, i.e. whether it is a primary diagnosis or whether the patient is presenting with recurrence. The definitive diagnosis can only be obtained by histological examination. Surgical removal of endometriotic foci is the gold standard to control symptoms [20-22]. When considering whether excision of endometrioma is indicated, the decision to opt for surgery must also take the subsequent reduction in ovarian reserve after repeat surgical excisions into account. Other indications for endoscopic therapy of recurrent endometriosis are pain resistant to therapy and organ destruction. If the patient's main focus is not on the pain but on her wish to have children, then, depending on the patient's age and ovarian reserve, after a primary diagnosis of endometriosis, the recommended approach in most cases is surgery to remove the endometriotic foci followed by a visit to a clinic for reproductive medicine. If the patient has rASRM stage I or II endometriosis, then ablation or excision of endometriotic foci can improve fertility [23]. A patient- and goal-oriented approach is essential to find an individual solution for the patient [24]. It is worth assessing whether the patient should participate in a study to help establish new therapeutic concepts $[25,26]$.

Medical hormone therapy should be prescribed postoperatively as prophylaxis and long-term therapy to prevent the recurrence of endometriosis $[18,27]$. Treatment options include pro- gestogen therapies, oral contraceptives (off-label use) and GnRH analogs [18].

Presentation to an outpatient pain clinic can be an additional therapeutic option for patients with persistent postoperative pain [28]. Other postoperative therapeutic options include physiotherapy, nutrition counselling and rehabilitation as well as individual therapeutic approaches such as osteopathy and traditional Chinese medicine (TCM). In addition to surgical and medical therapies, the interdisciplinary concept also includes the integration of psychosomatic therapies for patients with chronic lower abdominal pain and sterility.

A multidisciplinary approach is useful for patients with chronic lower abdominal pain $[29,30]$. The quality of life of affected patients and their ability to cope with chronic pain on a day-to-day basis can be significantly improved by the integration of psychosomatic care into their care plan, and this can ultimately also have a positive impact on treatment results [22,31].

A follow-up examination at the special endometriosis outpatient clinic or by the patient's regular gynecologist should be agreed upon with the patient to monitor the outcome of treatment.

\section{Descriptive analysis of treated patients}

This study analyzed patients with (symptoms suspicious for) endometriosis who presented to the special endometriosis outpatient clinic of the University Endometriosis Center Franken (UEF) between January 1, 2014 and December 31, 2016. Patients from this patient population who had surgery between January 1, 2014 and December 31, 2017 were selected for further analysis. The selected time period was extended by a further year to include those patients whose visit to the outpatient clinic resulted in an indication for surgery. Only patients who were operated in the 


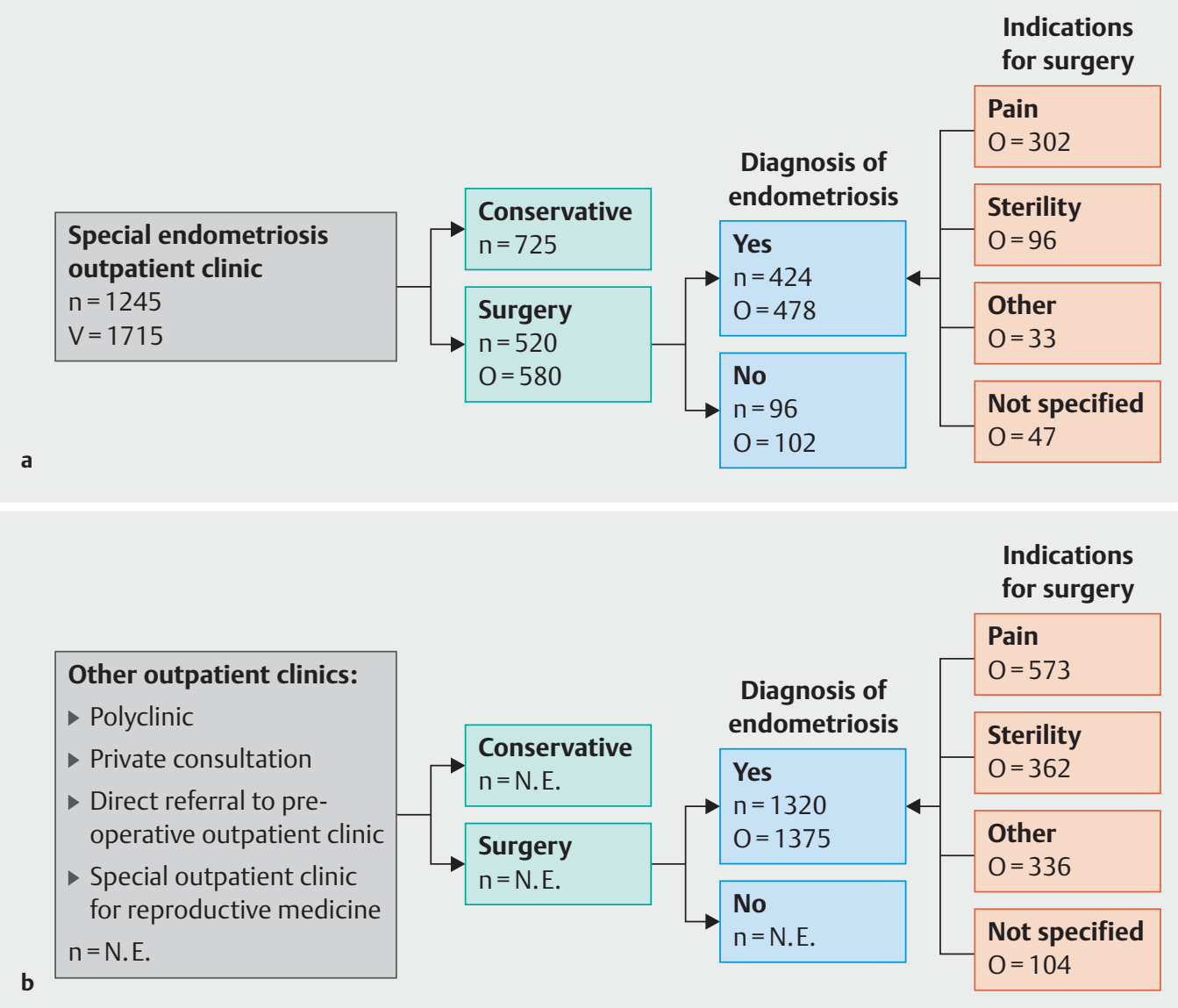

- Fig. 5 Description of patients who underwent surgery or were treated conservatively from a the special endometriosis outpatient clinic, and b other outpatient clinics. $\mathrm{n}=$ number of patients, $\mathrm{V}=$ number of outpatient visits; $\mathrm{O}=$ number of surgeries, $\mathrm{N}$. $\mathrm{E}$. = not evaluable.

\section{Results}

A total of 1245 patients with (symptoms suspicious for) endometriosis presented to the special endometriosis outpatient clinic between January 1, 2014 and December 31, 2016, with a total of 1715 visits to the outpatient clinic ( $\vee$ Fig. 5 a). 520 of these patients underwent surgery in the period between January 1, 2014 and December 31, 2017. Endometriosis was additionally diagnosed during surgery in a further 1375 patients in the period between January 1, 2014 and December 31, 2017. The patient cohort of operated patients from the special endometriosis outpatient clinic and from other outpatient clinics is described in - Table 1. All patients were treated in accordance with the diagnostic and therapeutic concept established by the UEF.

\section{Indications for surgery}

This study evaluated the patients attending the special endometriosis outpatient clinic who required surgery. More than one third of patients ( $41.8 \% ; n=520$ ) who presented to the special endometriosis outpatient clinic between 2014 and 2016 subsequently underwent surgery between 2014 and 2017 because of suspected endometriosis or recurrence of endometriosis ( $\vee$ Fig. 5 a).
Endometriosis was confirmed intraoperatively in 424 (81.5\%) of the 520 patients during 478 operations.

The main indication for surgery was pain $(70.1 \% ; n=302)$. Primary or secondary sterility was cited as the indication for surgery in $22.3 \%(n=96)$ of patients. Only $7.7 \%(n=33)$ of patients were operated on for other reasons such as suspicious ovarian findings. The number of re-operations in this period, i.e. the number of patients who underwent more than one operation, was 47 (9.8\%). Some of the repeat operations were carried out for recurrence of endometriosis. In other cases, repeat surgery was done because extensive intestinal endometriosis was found intraoperatively, and this finding required an interdisciplinary follow-up procedure with partial intestinal resection.

\section{Patient cohorts from other special outpatient clinics}

Between 2014 and 2017, 1853 operations were carried out at the Gynecology Department in 1744 patients with an intraoperative diagnosis of endometriosis. This results in a difference of 1320 patients who had surgery but did not present to the special endometriosis outpatient clinic preoperatively ( $\mathbf{F i g .} \mathbf{5} \mathbf{b})$. This cohort, which amounts to $75.7 \%$ of operated patients, consists of patients with an incidental finding of endometriosis during surgery for oth- 
- Table 1 Characteristics of patients with a diagnosis of endometriosis who underwent surgery.

\begin{tabular}{|c|c|c|c|}
\hline Parameter & $\begin{array}{l}\text { Special endometriosis } \\
\text { outpatient clinic }\end{array}$ & Other outpatient clinics & Total \\
\hline & $n=424$ & $n=1320$ & $n=1744$ \\
\hline Age at first surgery (years) & $32.9(7.8,399)^{*}$ & $34.9(8.3,1242)^{*}$ & $34.4(8.2,1642)^{*}$ \\
\hline Age at menarche (years) & $12.9(1.5,398)^{*}$ & $13.0(1.5,1179)^{*}$ & $12.9(1.5,1577)^{*}$ \\
\hline Cycle length at initial presentation (days) & $28.7(7.4,229)^{*}$ & $28.0(5.3,686)^{*}$ & $28.2(5.9,915)^{*}$ \\
\hline $\begin{array}{l}\text { Duration of menstrual flow at initial presentation } \\
\text { (days) }\end{array}$ & $5.4(1.6,279)^{*}$ & $5.4(1.9,896)^{*}$ & $5.4(1.8,1175)^{*}$ \\
\hline Body mass index at initial presentation $\left(\mathrm{kg} / \mathrm{m}^{2}\right)$ & $24.1(5.0,327)^{*}$ & $24.3(5.1,1060)^{*}$ & $24.3(5.1,1384)^{*}$ \\
\hline $\begin{array}{l}\text { Use of oral contraceptives (ever) at the time } \\
\text { of the initial presentation }\end{array}$ & $417(100 \%)$ & $1300(100 \%)$ & $1717(100 \%)$ \\
\hline - yes & $246(59.0 \%)$ & $476(36.6 \%)$ & $722(42.1 \%)$ \\
\hline - no & $6(1.4 \%)$ & $49(3.8 \%)$ & $55(3.2 \%)$ \\
\hline " unknown & $165(39.6 \%)$ & $775(59.6 \%)$ & $940(54.7 \%)$ \\
\hline $\begin{array}{l}\text { Use of oral contraceptives (currently) at the time } \\
\text { of initial presentation }\end{array}$ & $418(100 \%)$ & $1301(100 \%)$ & $1719(100 \%)$ \\
\hline - yes & $140(33.5 \%)$ & $305(23.4 \%)$ & $445(25.9 \%)$ \\
\hline - no & $272(65.1 \%)$ & 951 (73.1\%) & 1223 (71.0\%) \\
\hline - unknown & $6(1.4 \%)$ & $45(3.5 \%)$ & $51(3.0 \%)$ \\
\hline $\begin{array}{l}\text { Prevalent/incidental endometriosis } \\
\text { at initial presentation }\end{array}$ & 390 (100\%) & $1218(100 \%)$ & $1608(100 \%)$ \\
\hline - prevalent & $224(57.4 \%)$ & 194 (15.9\%) & $418(26.0 \%)$ \\
\hline - incidental & $166(42.6 \%)$ & 1024 (84.1\%) & $1250(74.0 \%)$ \\
\hline
\end{tabular}

er causes and patients who presented to other medical facilities such as special outpatient clinics for reproductive medicine, private consultations, polyclinics or directly to the preoperative outpatient clinic because of sterility or lower abdominal pain.

When evaluating the main indication for surgery, it turned out that pain was mentioned significantly less often (45.1\%). Sterility (28.5\%) and other reasons (26.4\%) were the other main indications for surgery and almost as important as pain.

The percentage of procedures performed laparoscopically (96.9\%), the percentage of histological confirmations of endometriosis $(90.0 \%)$ and the extent of endometriosis classified using the rASRM score were comparable with the percentages of the patients from the endometriosis outpatient clinic.

\section{Surgical procedure and intraoperative findings}

The overwhelming majority of surgical operations were carried out as laparoscopic procedures (95.9\%), although in ten cases the procedure had to change intraoperatively from laparoscopic surgery to laparotomy. Six of these ten operations were carried out as interdisciplinary procedures, and the reason for switching procedures was partial intestinal resection carried out in cooperation with another surgeon. In two cases, secondary laparotomy was performed for myoma enucleation and to remove a large myomatous uterus, respectively. The final two operations were carried out together with a urologist, with one patient under- going nephrectomy and one patient undergoing ureteric implantation for endometriosis.

$63.1 \%$ of cases had rASRM stage I-II disease. Histological confirmation was obtained in $93.7 \%$ of operations ( $\triangleright$ Table 2 ). Of the patients where no histological evaluation was carried out intraoperatively, 19 patients had an adenomatous uterus and hysterectomy was not carried out. Only two cases had macroscopic suspicion of endometriosis which was not confirmed histologically. The remaining cases where no histological investigation was carried out were two-stage surgeries. In these cases, extensive disease with deep infiltrating endometriosis was found during the first operation. The decision was then taken to discontinue surgery and to perform a second subsequent operation, during which the diagnosis was confirmed and partial intestinal resection or partial ureteric resection was carried out. Hysterectomy was carried out in $10.6 \%$ of recorded cases.

\section{Postoperative course}

After surgery, every patient was given a doctor's letter with written therapeutic recommendations. The recommendations included the proposed time of the postoperative follow-up examinations and, depending on the case, recommendations for medications to control symptoms and to prevent recurrence, or further procedures to be followed in cases with primary or secondary sterility. It was recommended that patients wishing to have children should attend a special outpatient clinic for reproductive medi- 
- Table 2 Description of surgical approach used.

\begin{tabular}{|c|c|c|c|}
\hline Parameter & $\begin{array}{l}\text { Special endometriosis } \\
\text { outpatient clinic }\end{array}$ & Other outpatient clinics & Total \\
\hline & $0=478$ & $0=1375$ & $0=1853$ \\
\hline Indications for surgery & $431(100 \%)$ & $1271(100 \%)$ & $1702(100 \%)$ \\
\hline - pain & $302(70.07 \%)$ & $573(45.1 \%)$ & $875(51.4 \%)$ \\
\hline - sterility & $96(22.27 \%)$ & $362(28.5 \%)$ & $458(26.9 \%)$ \\
\hline - other & $33(7.66 \%)$ & $336(26.4 \%)$ & $369(21.7 \%)$ \\
\hline Surgical approach & $441(100 \%)$ & $1273(100 \%)$ & $1714(100 \%)$ \\
\hline - minimally invasive & $423(95.9 \%)$ & $1233(96.9 \%)$ & $1656(96.6 \%)$ \\
\hline - laparotomy & $4(0.9 \%)$ & $16(1.3 \%)$ & $20(1.1 \%)$ \\
\hline - change of procedure intraoperatively & $10(2.3 \%)$ & $16(1.3 \%)$ & $26(1.5 \%)$ \\
\hline - other & $4(0.9 \%)$ & $7(0.5 \%)$ & $11(0.6 \%)$ \\
\hline - unknown & $0(0.0 \%)$ & $1(0.1 \%)$ & $1(0.1 \%)$ \\
\hline rASRM & $404(100 \%)$ & $1195(100 \%)$ & $1599(100 \%)$ \\
\hline - stage 0 & $21(5.2 \%)$ & $80(6.7 \%)$ & $101(6.3 \%)$ \\
\hline - stage I & $143(35.4 \%)$ & $564(47.2 \%)$ & 707 (44.2\%) \\
\hline - stage II & $93(23.0 \%)$ & $210(17.6 \%)$ & $303(18.9 \%)$ \\
\hline - stage III & $53(13.1 \%)$ & $146(12.2 \%)$ & $199(12.4 \%)$ \\
\hline - stage IV & $82(20.3 \%)$ & $132(11.0 \%)$ & $214(13.4 \%)$ \\
\hline . unknown & $12(3.0 \%)$ & $63(5.3 \%)$ & $75(4.7 \%)$ \\
\hline Deep infiltrating endometriosis & $442(100 \%)$ & $1275(100 \%)$ & $1717(100 \%)$ \\
\hline " yes & $327(74.0 \%)$ & $779(61.1 \%)$ & $1106(64.4 \%)$ \\
\hline - no & $112(25.3 \%)$ & $471(36.9 \%)$ & $583(34.0 \%)$ \\
\hline - unknown & $3(0.7 \%)$ & $25(2.0 \%)$ & $28(1.6 \%)$ \\
\hline Histological confirmation & $442(100 \%)$ & $1275(100 \%)$ & $1717(100 \%)$ \\
\hline - yes & $414(93.7 \%)$ & $1147(90.0 \%)$ & $1561(90.9 \%)$ \\
\hline . no & $28(6.3 \%)$ & $125(9.8 \%)$ & $153(8.9 \%)$ \\
\hline " unknown & $0(0.0 \%)$ & $3(0.2 \%)$ & $3(0.2 \%)$ \\
\hline Hysterectomy & $445(100 \%)$ & $1279(100 \%)$ & $1724(100 \%)$ \\
\hline - yes & $47(10.6 \%)$ & $153(12.0 \%)$ & $200(11.6 \%)$ \\
\hline . no & $398(89.4 \%)$ & $1126(88.0 \%)$ & $1524(88.4 \%)$ \\
\hline
\end{tabular}

cine. Postoperative follow-up examinations were carried out either at the Gynecology Department or by doctors in private practice. $16.0 \%(n=68)$ of patients from the special endometriosis outpatient clinic with confirmation of endometriosis who had undergone surgery returned to our clinic within one year for a (postoperative) follow-up examination. Most of these patients had undergone an interdisciplinary procedure in cooperation with a surgeon and urologist and required specific follow-up examinations.

\section{Discussion}

Standards for the process to be used by a special endometriosis outpatient clinic were developed at a certified clinical and scientific endometriosis center. These standards cover the specific clinical steps required to obtain a diagnosis, decide on the appropri- ate therapy and collect data for scientific purposes. The standards are based on the international recommendation of the $\mathrm{S} 2 \mathrm{k}$ guideline "Diagnosis and Therapy of Endometriosis" [20] and the European Society of Human Reproduction and Embryology [33]. A review of the literature showed that no comparable standardized approach for special endometriosis outpatient clinics has been published to date. There have been a number of international attempts to standardize the management of endometriosis and to compare national therapy recommendations. Every patient with endometriosis should be able to access diagnostic procedures and treatment tailored to her needs in certified specialist centers [34]. Careful detailed investigation of the patient's medical history can provide important information about the location of endometriotic foci which, taken together with the findings obtained during non-invasive diagnostic procedures, can confirm the suspicion of endometriosis $[35,36]$. The patient's medical history to- 
gether with a gynecological examination have a combined sensitivity of around $80 \%$ for diagnosing endometriosis, although only histological examination can provide the definitive confirmation of the diagnosis.

There is a symptom-based prognostic model which can be used to improve the selection of patients requiring surgery. The selection accuracy for patients who had surgery with histological confirmation of endometriosis was higher for patients with rASRM stages III and IV. By comparison, the predictive accuracy was much poorer for lower-stage endometriosis (stage I and II) [37]. In our study, endometriosis was confirmed in more than $80 \%$ of patients who underwent surgery. The extent of pain is not directly correlated with the location and extent of endometriosis [38, 39]. Our data were unable to confirm an increase in rASRM scores for patients with significant clinical symptoms (data not shown).

Some specialist societies support primary conservative medical treatment for women with mild to moderate lower abdominal pain who have regular ultrasound examinations $[33,40]$. However, there are no data which have shown that this approach is superior, and this approach should therefore only be agreed upon with patients on an individual basis.

A review of the indications for surgery provides information about the patient cohort presenting to the special endometriosis outpatient clinic. Non-specific lower abdominal pain was associated with endometriosis in up to half of all cases [35]. Our results showed that $70.1 \%$ of surgical procedures performed in patients from the special endometriosis outpatient clinic and $45.1 \%$ of operations carried out in patients from other outpatient clinics were performed because of pain. The low number of patients with sterility presenting to the special endometriosis outpatient clinic can be explained by the fact that patients with sterility usually first presented to the special outpatient clinic for gynecological endocrinology and reproductive medicine at the University Center for Reproduction Franken (UEF) and did not initially present to the endometriosis center. In the patient cohort from other outpatient clinics, the relatively low number of patients where pain was the main indication for surgery was because, in the majority of these patients, surgery was indicated for other findings such as myomatous uterus, ovarian cysts or sterility.

Surgical procedures to diagnose and alleviate endometriosis play a very important role. In terms of diagnosing endometriosis, no imaging procedures used to date offer results which are as accurate as surgery [41], meaning that surgical procedures remain the gold standard for diagnosing endometriosis. However, because of the possible negative consequences of this invasive approach such as adhesions, loss of functional ovarian tissue or damage to internal organs, it is important that in cases with recurrent endometriosis the recommendation for surgery is based on strict and restrictive criteria [24,42]. If stage rASRM I/II resectable endometriosis is found during surgical investigation for endometriosis, complete excision of endometriotic tissue should be done during the same procedure. Cases with rASRM stage III/IV endometriosis require an individual approach according to the main therapy goals agreed upon with the patient prior to surgery (pain relief vs. pregnancy). During the surgical removal of endometriotic tissue in a patient with ovarian endometriosis it is important to consider the best way of preserving ovarian reserve in the long term, particularly when treating patients who wish to have children.

Women below the age of 30 are reported to have a higher risk for repeat surgery for endometriosis [43]. The success of therapy in terms of improving pain symptoms is higher for the first operation compared to subsequent operations. Abboth et al. reported a decrease in pain symptoms of $83 \%$ in the first 6 months compared to $53 \%$ after subsequent operations [21]. Experienced surgeons, guideline-based recommendations for follow-up treatment, and the integration of interdisciplinary therapy concepts should reduce the rate of re-operations, although the well-known, disease-specific rate of recurrence reported for endometriosis must be taken into account [44]. Even after carrying out complete excision of endometriotic foci, recurrence rates of between $10 \%$ and $55 \%$ within the first 12 months after surgery have been reported [45].

To be able to deal appropriately with the above-mentioned circumstances, it is proposed that patients with a history of disease should be cared for in endometriosis centers. This is also reflected by our figures. After presenting to the special endometriosis outpatient clinic, excisional surgery was carried out $49.2 \%$ of all patients. These patients were already known to have endometriosis, and surgery was performed because of therapy-resistant pain. The majority of patients presenting to the special endometriosis outpatient clinic had already been treated previously for endometriosis, and this was also reflected in the percentage of patients taking oral contraceptives (59.1\%). By comparison, $89.9 \%$ of patients from other outpatient clinics did not have a previous surgical confirmation of endometriosis, and the percentage of them taking oral contraceptives as therapy was significantly lower (36.6\%). The quality criteria for surgery for patients from the special endometriosis outpatient clinic did not differ from that for patients from other outpatient clinics.

$96.6 \%$ of procedures were carried out as minimally invasive procedures. Magnification provides better visualization of the peritoneum, making it easier to detect and excise endometriotic foci. The intraoperative histological confirmation of the suspected diagnosis was high (90.9\%). The majority of cases where surgical procedures did not provide histological confirmation of the suspected diagnosis had uterine adenomyosis. Nor routine procedure has been established to confirm uterine adenomyosis, making it difficult to confirm adenomyosis surgically. A large percentage of cases in this patient population had deep infiltrating endometriosis, the majority of whom had uterine adenomyosis.

When a center becomes a certified endometriosis center, its quality criteria must also include postoperative follow-up. At present, $16.0 \%$ of patients who have a surgical procedure for endometriosis return to our clinic for their postoperative follow-up. Non-hospital-based gynecologists who cooperate with the endometriosis center by providing follow-up care for operated patients receive written therapy recommendations, thereby completing the postoperative care network. All operated patients who have no wish to have children and no contraindications should be offered prophylactic therapy against recurrence to reduce the recurrence of typical endometriosis-related complaints and prevent the development of endometrioma $[18,46]$. Patients who booked appointments with non-hospital-based gynecologists who are 
part of the care network were not included in this data evaluation, which may explain the low number of postoperative follow-up examinations carried out by the center.

This study aimed to present the standards for the process followed by a special endometriosis outpatient clinic and to evaluate a specific patient cohort. The study has both strengths and weaknesses. Setting up a special outpatient clinic and the corresponding data analysis is associated with higher costs for personnel and documentation and a greater expenditure of time and requires additional resources in terms of more personnel. However, the majority of patients who received an intraoperative diagnosis of endometriosis previously presented to other outpatient clinics. Diagnosis and treatment at these other outpatient clinics are in accordance with the same accepted standards, but because of the inconsistency with which outpatient visits are coded, the data of patients who present to those outpatient clinics with a suspicion of endometriosis or recurrence of endometriosis and are managed conservatively or for whom the suspected endometriosis was not confirmed intraoperatively cannot be evaluated. Moreover, the data does not yet show whether the patient presented to the outpatient clinic at the recommendation of her gynecologist, of an outpatient endometriosis clinic or on her own initiative. If this information were available, it could be used to develop a targeted process to attract more patients to the endometriosis outpatient clinic and focus more attention on the topic of endometriosis.

The strengths of the study include the high number of treated patients and the fact that use of a scientific questionnaire made it possible to analyze the characteristics of operated patients. The clinic's structure represents a marketing tool to recruit patients to the center and maintain a long-term relationship with patients.

The standards for the special endometriosis outpatient clinic published here are also relevant for routine gynecological practice. They ensure that the choice of therapy is patient-centered and goal-oriented. This was demonstrated by the high level of sensitivity for the indications for surgery. The concept presented in this study should serve as an example and can be implemented or adapted by other endometriosis centers according to their infrastructure. As the recommendations for a standardized therapy algorithm for women with endometriosis are, in some cases, still inconsistent, the algorithm presented here aimed to fill this gap. Attending an outpatient clinic encourages a relationship of trust and creates a bond between the patient and the clinic where she is treated. Patients benefit from undergoing surgery at a certified center for endometriosis which follows standardized processes, with patients profiting from the clinical and scientific expertise and the quality-assured transparent structures and processes created during certification.

\section{Conflict of Interest}

The authors declare that they have no conflict of interest.

\section{References}

[1] Saha R, Kuja-Halkola R, Tornvall P et al. Reproductive and Lifestyle Factors Associated with Endometriosis in a Large Cross-Sectional Population Sample. J Womens Health (Larchmt) 2017; 26: 152-158

[2] Sarıdoğan E. Adolescent endometriosis. Eur J Obstet Gynecol Reprod Biol 2017; 209: 46-49

[3] Mahmood TA, Templeton A. Prevalence and genesis of endometriosis. Hum Reprod 1991; 6: 544-549

[4] Witz CA, Burns WN. Endometriosis and infertility: is there a cause and effect relationship? Gynecol Obstet Invest 2002; 53 (Suppl. 1): 2-11

[5] Viganò P, Parazzini F, Somigliana E et al. Endometriosis: epidemiology and aetiological factors. Best Pract Res Clin Obstet Gynaecol 2004; 18: 177-200

[6] Buck Louis GM, Hediger ML, Peterson CM et al.; ENDO Study Working Group. Incidence of endometriosis by study population and diagnostic method: the ENDO study. Fertil Steril 2011; 96: 360-365

[7] Hudelist G, Fritzer N, Thomas A et al. Diagnostic delay for endometriosis in Austria and Germany: causes and possible consequences. Hum Reprod 2012; 27: 3412-3416

[8] Simoens S, Hummelshoj L, D’Hooghe T. Endometriosis: cost estimates and methodological perspective. Hum Reprod Update 2007; 13: 395404

[9] Nnoaham KE, Hummelshoj L, Webster P et al.; World Endometriosis Research Foundation Global Study of Women's Health consortium. Impact of endometriosis on quality of life and work productivity: a multicenter study across ten countries. Fertil Steril 2011; 96: 366-373.e8

[10] Simoens S, Dunselman G, Dirksen C et al. The burden of endometriosis: costs and quality of life of women with endometriosis and treated in referral centres. Hum Reprod 2012; 27: 1292-1299

[11] Soliman AM, Surrey E, Bonafede M et al. Real-World Evaluation of Direct and Indirect Economic Burden Among Endometriosis Patients in the United States. Adv Ther 2018; 35: 408-423

[12] Ebert AD, Ulrich U, Keckstein J et al.; Endometriosis Research Foundation, and the European Endometriosis League. Implementation of certified endometriosis centers: 5 -year experience in German-speaking Europe. Gynecol Obstet Invest 2013; 76: 4-9

[13] Thiel FC, Scharl A, Hildebrandt T et al. Financing of certified centers: a willingness-to-pay analysis. Arch Gynecol Obstet 2013; 287: 495-509

[14] Hudelist G, Fritzer N, Staettner $S$ et al. Uterine sliding sign: a simple sonographic predictor for presence of deep infiltrating endometriosis of the rectum. Ultrasound Obstet Gynecol 2013; 41: 692-695

[15] Exacoustos C, Manganaro L, Zupi E. Imaging for the evaluation of endometriosis and adenomyosis. Best Pract Res Clin Obstet Gynaecol 2014; 28: 655-681

[16] Van den Bosch T, Dueholm M, Leone FP et al. Terms, definitions and measurements to describe sonographic features of myometrium and uterine masses: a consensus opinion from the Morphological Uterus Sonographic Assessment (MUSA) group. Ultrasound Obstet Gynecol 2015; 46: 284-298

[17] Bazot M, Lafont C, Rouzier R et al. Diagnostic accuracy of physical examination, transvaginal sonography, rectal endoscopic sonography, and magnetic resonance imaging to diagnose deep infiltrating endometriosis. Fertil Steril 2009; 92: 1825-1833

[18] Lermann J, Hackl J, Burghaus S et al. Die medikamentöse Therapie der Patientin mit Endometriose. Frauenheilkunde up2date 2017; 11: 27-41

[19] Renner SP, Lermann J, Burghaus S et al. Die operative Therapie der Endometriose. Frauenheilkunde up2date 2016; 10: 311-330

[20] Ulrich U, Buchweitz O, Greb R et al.; German and Austrian Societies for Obstetrics and Gynecology. National German Guideline (S2k): Guideline for the Diagnosis and Treatment of Endometriosis: Long Version - AWMF Registry No. 015-045. Geburtsh Frauenheilk 2014; 74: 1104-1118 
[21] Abbott ], Hawe ], Hunter D et al. Laparoscopic excision of endometriosis: a randomized, placebo-controlled trial. Fertil Steril 2004; 82: 878-884

[22] Deguara CS, Pepas L, Davis C. Does minimally invasive surgery for endometriosis improve pelvic symptoms and quality of life? Curr Opin Obstet Gynecol 2012; 24: 241-244

[23] Jacobson TZ, Duffy JM, Barlow D et al. Laparoscopic surgery for subfertility associated with endometriosis. Cochrane Database Syst Rev 2010; (1): CD001398

[24] Singh SS, Suen MW. Surgery for endometriosis: beyond medical therapies. Fertil Steril 2017; 107: 549-554

[25] Barra F, Ferrero S. mTor Inhibitors for the Treatment of Endometriosis. Geburtsh Frauenheilk 2018; 78: 283-284

[26] Kacan T, Yildiz C, Baloglu Kacan S et al. Everolimus as an mTOR Inhibitor Suppresses Endometriotic Implants: an Experimental Rat Study. Geburtsh Frauenheilk 2017; 77: 66-72

[27] Petraglia F, Hornung D, Seitz C et al. Reduced pelvic pain in women with endometriosis: efficacy of long-term dienogest treatment. Arch Gynecol Obstet 2012; 285: 167-173

[28] Oladosu FA, Tu FF, Hellman KM. Nonsteroidal antiinflammatory drug resistance in dysmenorrhea: epidemiology, causes, and treatment. Am J Obstet Gynecol 2018; 218: 390-400

[29] Butrick CW. Chronic pelvic pain: how many surgeries are enough? Clin Obstet Gynecol 2007; 50: 412-424

[30] Lovrincevic M. Chronic pelvic pain in women of childbearing age. Curr Opin Anaesthesiol 2003; 16: 275-280

[31] Siedentopf F, Tariverdian N, Rücke M et al. Immune status, psychosocial distress and reduced quality of life in infertile patients with endometriosis. Am J Reprod Immunol 2008; 60: 449-461

[32] Burghaus S, Fehm T, Fasching PA et al. The International Endometriosis Evaluation Program (IEEP Study) - A Systematic Study for Physicians, Researchers and Patients. Geburtsh Frauenheilk 2016; 76: 875-881

[33] Dunselman GA, Vermeulen N, Becker C et al.; European Society of Human Reproduction and Embryology. ESHRE guideline: management of women with endometriosis. Hum Reprod 2014; 29: 400-412

[34] Johnson NP, Hummelshoj L. Consensus on current management of endometriosis. Hum Reprod 2013; 28: 1552-1568
[35] Fauconnier A, Chapron C. Endometriosis and pelvic pain: epidemiological evidence of the relationship and implications. Hum Reprod Update 2005; 11: 595-606

[36] Vercellini P, Giudice LC, Evers JL et al. Reducing low-value care in endometriosis between limited evidence and unresolved issues: a proposal. Hum Reprod 2015; 30: 1996-2004

[37] Nnoaham KE, Hummelshoj L, Kennedy SH et al.; World Endometriosis Research Foundation Women's Health Symptom Survey Consortium. Developing symptom-based predictive models of endometriosis as a clinical screening tool: results from a multicenter study. Fertil Steril 2012; 98: 692-701.e5

[38] Vercellini P, Trespidi L, De Giorgi O et al. Endometriosis and pelvic pain: relation to disease stage and localization. Fertil Steril 1996; 65: 299-304

[39] Renner SP, Boosz AS, Burghaus S et al. Visual pain mapping in endometriosis. Arch Gynecol Obstet 2012; 286: 687-693

[40] Practice Committee of the American Society for Reproductive Medicine. Treatment of pelvic pain associated with endometriosis: a committee opinion. Fertil Steril 2014; 101: 927-935

[41] Nisenblat V, Bossuyt PM, Farquhar C et al. Imaging modalities for the non-invasive diagnosis of endometriosis. Cochrane Database Syst Rev 2016; (2): CD009591

[42] Janssen EB, Rijkers AC, Hoppenbrouwers K et al. Prevalence of endometriosis diagnosed by laparoscopy in adolescents with dysmenorrhea or chronic pelvic pain: a systematic review. Hum Reprod Update 2013; 19 : 570-582

[43] Shakiba K, Bena JF, McGill KM et al. Surgical treatment of endometriosis: a 7-year follow-up on the requirement for further surgery. Obstet Gynecol 2008; 111: 1285-1292

[44] Renner SP, Rix S, Boosz A et al. Preoperative pain and recurrence risk in patients with peritoneal endometriosis. Gynecol Endocrinol 2010; 26: 230-235

[45] Vercellini P, Somigliana E, Viganò $P$ et al. The effect of second-line surgery on reproductive performance of women with recurrent endometriosis: a systematic review. Acta Obstet Gynecol Scand 2009; 88: 1074-1082

[46] Zorbas KA, Economopoulos KP, Vlahos NF. Continuous versus cyclic oral contraceptives for the treatment of endometriosis: a systematic review. Arch Gynecol Obstet 2015; 292: 37-43 